\title{
From Core-Shell to Alloys: The Preparation and Characterization of Solution-Synthesized AuPd Nanoparticle Catalysts
}

\author{
Adria R. Wilson, ${ }^{\dagger}$ Keyi Sun, ${ }^{\ddagger}$ Miaofang Chi, ${ }^{\S}$ Ryan M. White, ${ }^{\|}$James M. LeBeau, ${ }^{\|}$H. Henry Lamb, ${ }^{*} \neq$ \\ and Benjamin J. Wiley* ${ }^{\dagger}$ \\ ${ }^{\dagger}$ Department of Chemistry, Duke University, 124 Science Drive, Box 90354, Durham, North Carolina 27708, United States
${ }^{\ddagger}$ Department of Chemical and Biomolecular Engineering, North Carolina State University, Box 7905, Raleigh, North Carolina 27695,
United States \\ ${ }^{\S}$ Microscopy Group, Oak Ridge National Laboratory, 1 Bethel Valley Road, Building 4515, MS 6064 Oak Ridge, Tennessee 37831, \\ United States \\ "Department of Materials Science \& Engineering, North Carolina State University, Box 7907, Raleigh, North Carolina 27695, United \\ States
}

Supporting Information

\begin{abstract}
This article describes the solution-phase synthesis of $4 \mathrm{~nm}$ gold nanoparticles with 0.7 atom-thick, 1.9 atom-thick, and 3.8 atom-thick layers of Pd on their surfaces. These well-defined core-shell nanoparticles were deposited on a silica support, calcined, and reduced at $300{ }^{\circ} \mathrm{C}$ to create alloyed nanoparticles containing 10.9, 20.2, and $28.5 \% \mathrm{Pd}(\mathrm{w} / \mathrm{w})$. Monometallic Pd nanoparticles sintered during calcination at $300{ }^{\circ} \mathrm{C}$, but no sintering was observed for AuPd nanoparticles. Diffuse reflectance infrared Fourier transform (DRIFT) spectra of adsorbed CO suggests that Au donates $d$
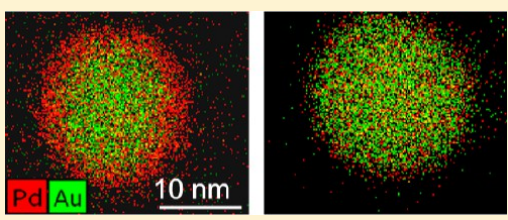

electron density to $\mathrm{Pd}$ in the core-shell and alloy structures and confirms the presence of $\mathrm{Au}$ and $\mathrm{Pd}$ atoms on the surface of the nanoparticles after calcination and reduction. The properties of the AuPd alloy catalysts were tested in the vapor-phase conversion of $\alpha$-limonene to $p$-cymene. AuPd nanoparticles containing 20\% or more Pd per particle produced $p$-cymene yields greater than $80 \%$, equivalent to conventional $\mathrm{Pd}$ catalysts prepared by incipient wetness and ion exchange methods. Very low yields of $p$-cymene were obtained from dehydrogenation of $p$-menthane under equivalent conditions, suggesting that the production of $p$-cymene from $\alpha$-limonene proceeds through terpinene intermediates.
\end{abstract}

\section{INTRODUCTION}

Alloy catalysts can offer greater reaction-specific catalyst tunability, lower cost, and higher performance than their monometallic counterparts. The study of alloy catalysts offer scientists the opportunity to better understand how the interplay between different metals in the nanoregime affects the outcome of heterogeneously catalyzed chemical reactions. AuPd catalysts have been of particular interest not only because of the wide range of reactions in which they can be used but also because of their relative simplicity. ${ }^{1} \mathrm{Au}$ and $\mathrm{Pd}$ are soluble at all compositions, so that the effects of different phases need not be considered. ${ }^{2,3}$ In many reactions, Au is catalytically inert, so any catalytic activity can be ascribed to Pd. To date, a variety of mechanisms have been proposed for the greater catalytic activity and selectivity of AuPd compared to Pd alone. ${ }^{4-7}$ Enache and co-workers found that $\mathrm{AuPd} / \mathrm{TiO}_{2}$ is twice as productive as $\mathrm{Pd}$ for benzyl alcohol conversion to benzaldehyde and proposed that $\mathrm{Au}$ is an electronic promoter of $\mathrm{Pd} .{ }^{4}$ Vinyl acetate monomer production is enhanced 13-fold over 1:4 $\mathrm{AuPd} / \mathrm{SiO}_{2}$ nanoparticles relative to $\mathrm{Pd} / \mathrm{SiO}_{2}$, and this has been attributed to changes in the electronic and geometric properties of Pd upon alloying with Au. ${ }^{8}$ Studies of vinyl acetate formation rates over submonolayers of Pd on single-crystal gold surfaces suggest isolated pairs of $\mathrm{Pd}$ on $\mathrm{Au}(100)$ enhance binding of acetate with ethylene, and suppress the formation of reaction byproducts. $^{8}$ An AuPd $/ \mathrm{SiO}_{2}$ catalyst with 0.2 monolayer coverage of $\mathrm{Pd}$ hydrogenated propene with 12 times the activity of $\mathrm{Pd}$ alone; the authors proposed Au breaks up 3-fold surface sites of $\mathrm{Pd}$, and thereby increases the formation of highly reactive propylene relative to less reactive propylidene. ${ }^{9}$ Similar enhancements of AuPd relative to Pd are observed in many other reactions. ${ }^{10-17}$ These examples suggest that the specific way in which Au enhances Pd activity varies depending on the reaction being catalyzed and that a clearer, more general depiction of the mechanisms by which AuPd exhibits relatively greater activity, selectivity, and stability will begin to emerge only after examining its properties in a wide variety of reactions.

The conventional wet-impregnation and coprecipitation methods used in many of the studies cited above result in a catalyst structure consisting of nanoparticles with a range of sizes and compositions. The ambiguous structures of these catalysts make it difficult to map out their structure-dependent properties. Various authors have developed colloidal methods in an attempt to produce well-defined nanoparticle cata-

Received: April 26, 2013

Revised: July 8, 2013

Published: July 9, 2013 
lysts. ${ }^{2,13,17-19}$ However, previous efforts to produce polymerfree (calcined), oxide-supported AuPd nanoparticles in a catalytically relevant size range $(\leq 5 \mathrm{~nm}$ in diameter) have resulted in nanoparticles with an unknown range of compositions and with standard deviations in particle size on the order of the nanoparticle diameter. ${ }^{17,20}$ Thus, despite the numerous articles focused on AuPd, there remains a need for methods that produce model AuPd catalysts consisting of nanoparticles with a very narrow range of sizes and compositions.

We have used solution-phase synthesis to produce a series of polyvinylpyrrolidone (PVP)-stabilized AuPd core-shell nanoparticles that have palladium shell thicknesses of $0.7 \pm 0.2,1.9$ \pm 0.3 , and $3.8 \pm 0.8$ atomic monolayers of $\mathrm{Pd}$ as calculated from high-angle annular dark field scanning transmission electron microscopy (HAADF-STEM) images. The coreshell nanoparticles were deposited on a silica support and transformed into alloyed nanoparticles consisting of $10.9 \pm 2.3$, $20.2 \pm 4.3$, and $28.5 \pm 6.0 \%$ Pd per nanoparticle, respectively, through calcination and reduction at $300{ }^{\circ} \mathrm{C}$. An advantage of using a core-shell precursor to produce alloyed nanoparticles is that it facilitates the determination of the per-particle $\mathrm{Pd}$ content by measuring changes in shell thickness via standard bright-field TEM and HAADF-STEM. This study represents the first attempt to characterize the structure and properties of AuPd catalysts made by heating and alloying core-shell AuPd nanoparticles.

We examined the catalytic properties of these AuPd alloy catalysts, along with conventionally prepared $\mathrm{Au} / \mathrm{SiO}_{2}$ and $\mathrm{Pd} /$ $\mathrm{SiO}_{2}$ catalysts, in the conversion of limonene to $p$-cymene. Currently, $p$-cymene is produced from petroleum for use in resins, fragrances, pesticides, and solvents. ${ }^{21-24} \mathrm{~A}$ more environmentally friendly process is to produce cymene from $\alpha$-limonene, an abundant waste product of the citrus juice industry. ${ }^{22}$ Both $\mathrm{Pd}$ and Au have been tested as monometallic catalysts for the conversion of limonene to $p$-cymene. $\mathrm{Pd}$ catalyzes the conversion of limonene to $p$-cymene with high selectivity, but $\mathrm{Au}$ exhibits almost no activity. ${ }^{22}$ A proposed mechanism for the production of $p$-cymene over $\mathrm{Pd} / \mathrm{SiO}_{2}$ is through the dehydrogenation of $p$-menthane. ${ }^{22,25}$ The performance of supported AuPd catalysts for limonene conversion has not been tested. We have chosen to study the activity of supported AuPd nanoparticles in limonene conversion not only to explore their potential as catalysts for the production of $p$ cymene from waste but also to gain additional insights into the Pd-catalyzed conversion mechanism using these well-defined alloy catalysts.

\section{EXPERIMENTAL METHODS}

Chemicals. Gold(III) chloride trihydrate (520918), sodium citrate tribasic dihydrate (S4641), sodium tetrachloropalladate(II) (205818), hydroquinone (H9003), polyvinylpyrrolidone $\mathrm{MW}=55,000$ (856568, PVP55), and polyvinylpyrrolidone MW $=29,000$ (234257, PVP29) were purchased from SigmaAldrich. Hydrochloric acid (UN1789) and $p$-menthane (32053122) were purchased from Fisher Scientific. Limonene (10162783), p-cymene (A0300974), acetone (BDH11014LP), ethanol (UN1170), terpinolene (TCT0817-025 ML), $\alpha$-terpinene (TCM0317-025 ML), and $\gamma$-terpinene (TCM0318-025 ML) were purchased from VWR. Palladium(II) nitrate hydrate (22403000) and palladium tetrammine dinitrate (19843400) were purchased from Strem Chemical, and the silica used for all of the catalysts was Aerosil 300 from
Degussa (specific surface area $=300 \mathrm{~m}^{2} / \mathrm{g}$ ). All chemicals were used without further purification.

Synthesis of Au Nanoparticles. Stirring rapidly, $980 \mu \mathrm{L}$ of $1 \%(\mathrm{w} / \mathrm{w}) \mathrm{HAuCl}_{4}(\mathrm{aq})$ solution was added to $100 \mathrm{~mL}$ of DI $\mathrm{H}_{2} \mathrm{O}$ in a round-bottom flask. To this, $740 \mu \mathrm{L}$ of $1 \%(\mathrm{w} / \mathrm{v})$ sodium citrate and $3 \mathrm{~mL}$ of $0.1 \mathrm{M} \mathrm{NaBH}_{4}(\mathrm{aq})$ were added in immediate succession. The $\mathrm{NaBH}_{4}(\mathrm{aq})$ solution was chilled to $0{ }^{\circ} \mathrm{C}$ in an ice bath prior to use. Upon the addition of $\mathrm{NaBH}_{4}(\mathrm{aq})$, the solution immediately turned pink-orange in color, indicating nanoparticle formation. The solution was left to sit for $1 \mathrm{~h}$ before use, during which time it turned bright red.

Synthesis of $0.7,1.9$, and 3.8 ML Pd@Au Nanoparticles. Making AuPd core-shell particles with different shell thicknesses required varying the amounts of reducing agent and $\mathrm{Pd}$ introduced to the $\mathrm{Au}$ seed particle solution. In each case, the $\mathrm{Au}$ seed solution was stirred at $450 \mathrm{rpm}$ and room temperature, and the reactions were run for $3 \mathrm{~h}$ after the initial addition of Pd. For $0.7 \mathrm{Pd} @ \mathrm{Au}, 2 \mathrm{~mL}$ of $1 \%(\mathrm{w} / \mathrm{v})$ hydroquinone was added to $100 \mathrm{~mL}$ of $\mathrm{Au}$ seed solution, and $2.5 \mathrm{~mL}$ of $2 \mathrm{mM}$ aqueous disodium tetrachloropalladate $\left(\mathrm{Na}_{2} \mathrm{PdCl}_{4}(\mathrm{aq})\right)$ was infused into the solution at $67 \mu \mathrm{L} / \mathrm{min}$. The 1.9 Pd@Au particles were synthesized in $50 \mathrm{~mL}$ batches so that the $\mathrm{Na}_{2} \mathrm{PdCl}_{4}$ solution could be completely infused at the same rate $(67 \mu \mathrm{L} / \mathrm{min})$ within the three-hour reaction time. In this case, $1 \mathrm{~mL}$ of $1 \%$ hydroquinone was added followed by the infusion of $9.65 \mathrm{~mL}$ of $2 \mathrm{mM} \mathrm{Na}_{2} \mathrm{PdCl}_{4}($ aq $)$ at $67 \mu \mathrm{L} / \mathrm{min}$. To make the 3.8 Pd@Au particles, $4 \mathrm{~mL}$ of 1\% hydroquinone and $2 \mathrm{~mL}$ of $20 \mathrm{mM} \mathrm{Na} \mathrm{PdCl}_{4}$ (aq) were added, the $\mathrm{Pd}$ solution being introduced all at once. At the end of the reaction, $2 \mathrm{~mL}$ of $1 \%(\mathrm{w} / \mathrm{v}) \mathrm{HCl}(\mathrm{aq})$ was pipetted into $100 \mathrm{~mL}$ of the 0.7 and 1.9 Pd@Au solutions, or $4 \mathrm{~mL}$ of $1 \%(\mathrm{w} / \mathrm{v}) \mathrm{HCl}$ (aq) into $100 \mathrm{~mL}$ of the 3.8 Pd@Au solution, to stop the reaction, followed by 4 $\mathrm{mL}$ of $1 \%(\mathrm{w} / \mathrm{v})$ PVP55 aqueous solution to stabilize the particles.

Synthesis of Pd Nanoparticles. PVP-stabilized Pd nanoparticles were synthesized via a method based on work by $\mathrm{Han}$ et al. ${ }^{26}$ After heating $100 \mathrm{~mL}$ of $\mathrm{DI} \mathrm{H}_{2} \mathrm{O}$ to boiling in a round-bottom flask fit with a reflux condenser, $1.06 \mathrm{~g}$ of PVP29 was added, followed by $3 \mathrm{~mL}$ of $2 \mathrm{M} \mathrm{HCl}(\mathrm{aq})$. Once the reaction was refluxing, $0.53 \mathrm{~mL}$ of $0.47 \mathrm{M} \mathrm{Na}_{2} \mathrm{PdCl}_{4}$ (aq) was added, and $80 \mathrm{~mL}$ of $\mathrm{EtOH}$ was poured in slowly. The reaction refluxed for $3 \mathrm{~h}$ before being removed from heat.

Incipient Wetness Preparation of $\mathrm{Pd} / \mathrm{SiO}_{2}$ (iw). A $1.78 \%$ (w/w) $\mathrm{Pd} / \mathrm{SiO}_{2}$ (iw) catalyst was prepared by incipient wetness impregnation. An aqueous solution of $0.2 \mathrm{~g}$ of $\mathrm{Pd}\left(\mathrm{NO}_{3}\right)_{2}$ dissolved in $19.0 \mathrm{~mL}$ of $\mathrm{DI} \mathrm{H}_{2} \mathrm{O}$ was added to $4 \mathrm{~g}$ of silica. The resultant material was dried in an oven in air at $40{ }^{\circ} \mathrm{C}$ overnight, then calcined under flowing $\mathrm{O}_{2}(\mathrm{~g})$ at $300{ }^{\circ} \mathrm{C}$ for $2 \mathrm{~h}$, ramping the temperature to the set point at a rate of $5{ }^{\circ} \mathrm{C} / \mathrm{min}$.

Ion Exchange Preparation of $\mathrm{Pd} / \mathrm{SiO}_{2}$ (ie). A $0.6 \%(w /$ w) $\mathrm{Pd} / \mathrm{SiO}_{2}$ sample was prepared by ion exchange $\left(\mathrm{Pd} / \mathrm{SiO}_{2}\right.$ (ie)). Silica powder was mixed with $50 \mathrm{~mL}$ of $\mathrm{DI} \mathrm{H}_{2} \mathrm{O}$ to form a suspension. Pd ions were added by dropwise addition of a solution of $1.6 \mathrm{~g}$ of $\mathrm{Pd}\left[\left(\mathrm{NH}_{3}\right)_{4}\right]\left(\mathrm{NO}_{3}\right)_{2}$ in $40 \mathrm{~mL}$ of DI $\mathrm{H}_{2} \mathrm{O}$. The $\mathrm{pH}$ of the solution was 9 and was not adjusted to be otherwise. Afterward, the solvent was removed by filtration, and the catalyst was washed three times with $\mathrm{DI} \mathrm{H}_{2} \mathrm{O}$ before being dried in an oven at $100{ }^{\circ} \mathrm{C}$ overnight. The catalyst was then calcined under flowing $\mathrm{O}_{2}(\mathrm{~g})$ with a temperature ramp of 0.5 ${ }^{\circ} \mathrm{C} / \mathrm{min}$ from room temperature to $250{ }^{\circ} \mathrm{C}$, where it was held for $2 \mathrm{~h}$.

Catalyst Preparation. Silica-supported nanoparticle catalysts were made by first concentrating each nanoparticle 
solution 4-fold by flowing nitrogen over the surface of the stirring solution. Silica was plasma cleaned for an hour prior to being dispersed in solvent and combined with the concentrated nanoparticle solution. The mixture was centrifuged to precipitate out the catalyst as a gel. For the AuPd NP and $\mathrm{Au}$ NP catalysts, $0.27 \mathrm{~g}$ of plasma-cleaned silica was dispersed in $20 \mathrm{~mL}$ of $\mathrm{DI} \mathrm{H}_{2} \mathrm{O}$ and was centrifuged at $15,000 \mathrm{rpm}$ for $1 \mathrm{~h}$. The precipitated catalyst was washed two times in $15 \mathrm{~mL}$ of DI $\mathrm{H}_{2} \mathrm{O}$ after this initial centrifugation step at $15,000 \mathrm{rpm}$ for 20 min to remove any unreacted Pd ion or excess PVP55 from the catalyst. Each batch of Pd NPs was mixed with $0.73 \mathrm{~g}$ of plasma-cleaned silica dispersed in $80 \mathrm{~mL}$ of acetone. This sample was not washed after centrifugation because aggregation of the nanoparticles was observed after a second centrifugation step. After centrifugation, the catalysts were dried under vacuum at $100{ }^{\circ} \mathrm{C}$ for $5 \mathrm{~h}$. For each catalyst prepared from a colloidal nanoparticle solution, the number of nanoparticles per liter of solution per gram of silica was kept at a constant value of $1.01 \times 10^{18} \mathrm{NP} / \mathrm{L} \mathrm{g}$.

Catalyst Pretreatment. Prior to testing, the catalysts were calcined in a tube furnace at $300{ }^{\circ} \mathrm{C}$ for $1 \mathrm{~h}$ under an $\mathrm{O}_{2}(\mathrm{~g})$ flow of $0.6 \mathrm{~L} / \mathrm{min}$. The temperature was increased to $300{ }^{\circ} \mathrm{C}$ at a rate of $5{ }^{\circ} \mathrm{C} / \mathrm{min}$. These calcination conditions have previously been shown to remove PVP from AuPd catalysts. ${ }^{9}$ For samples used in limonene conversion and for TEM analysis, the catalyst was reduced at $300{ }^{\circ} \mathrm{C}$ for $1 \mathrm{~h}$ in situ under a stream of $100 \% \mathrm{H}_{2}(\mathrm{~g})$ flowing at $50 \mathrm{sccm}$. For characterization with DRIFTS, the catalysts were reduced under $30 \mathrm{sccm}$ $10 \% \mathrm{H}_{2}(\mathrm{~g})$ in $\mathrm{He}(\mathrm{g})$ for $1 \mathrm{~h}$, and then under $30 \mathrm{sccm} 100 \%$ $\mathrm{He}(\mathrm{g})$ for $30 \mathrm{~min}$.

Catalyst Characterization. Bright-field TEM images of each catalyst were acquired with a Tecnai FEI $\mathrm{G}^{2}$ twin microscope at Duke University, and high-resolution HAADFSTEM images were taken using the JEOL 2010F located at Oak Ridge National Laboratory in Oak Ridge, Tennessee, and the FEI Titan STEM at North Carolina State University. DRIFTS spectra were acquired using a Bruker Optics Vertex 70 FT-IR spectrometer equipped with a Harrick Praying Mantis Diffuse Reflection Accessory with a Praying Mantis High Temperature Reaction Chamber in situ reaction cell and OPUS data analysis software. CO chemisorption measurements were made using a Micromeritics ASAP 2020 Surface Area and Porosity Analyzer to determine active surface area on the catalyst. For CO chemisorption experiments, the catalysts were reduced at 300 ${ }^{\circ} \mathrm{C}$ in $\mathrm{H}_{2}(\mathrm{~g})$ during analysis. Difference results (total $\mathrm{CO}-$ weakly adsorbed $\mathrm{CO}$ ) are reported. Inductively coupled plasma atomic emission spectroscopy (ICP-AES) analysis was performed by Galbraith Laboratories.

Limonene and Menthane Reactor Conditions. The limonene and menthane conversion reactions were carried out in a homemade vapor phase glass tube reactor coupled to an HP 5890 Series II gas chromatograph. For each run, $250 \mathrm{mg}$ of calcined catalyst was loaded into the reactor, where it was reduced under $50 \mathrm{sccm} \mathrm{H}_{2}(\mathrm{~g})$ at $300{ }^{\circ} \mathrm{C}$ for $1 \mathrm{~h}$. Immediately after reduction, the reactor temperature was dropped to 250 ${ }^{\circ} \mathrm{C}$, and $\alpha$-limonene or $p$-menthane was continuously injected by syringe pump (Harvard Instruments) at $6 \mu \mathrm{L} / \mathrm{min}$. All lines were kept at $220{ }^{\circ} \mathrm{C}$. The GC utilized an FID detector, and the oven temperature was maintained at $80{ }^{\circ} \mathrm{C}$, with $\mathrm{He}(\mathrm{g})$ as the carrier gas through a Restek Stabiliwax Bonded Packed Column (Cat\# 80416-810). Injections were performed every $10 \mathrm{~min}$. Once the reactor temperature and the feed flow stabilized, the reactor was run between 1.5 and $3 \mathrm{~h}$.

\section{RESULTS AND DISCUSSION}

Characterizing the Pd@Au NP Structure. Figure 1 shows high-resolution HAADF-STEM images of the three core-shell
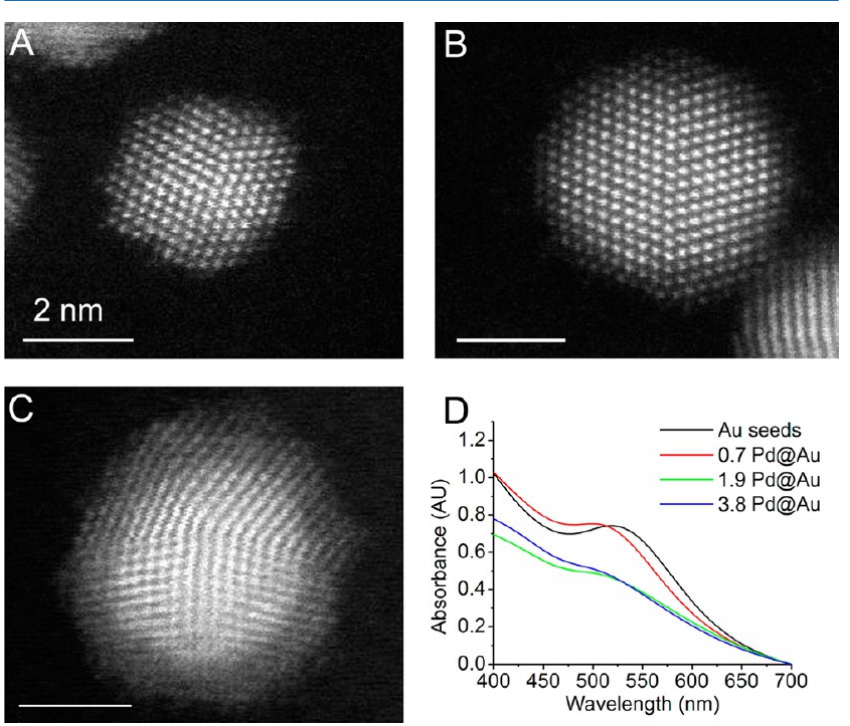

Figure 1. HAADF-STEM images of (A) 0.7 Pd@Au, (B) 1.9 Pd@Au, and (C) 3.8 Pd@Au nanoparticles after synthesis. Panel D shows the $\mathrm{UV}$-visible spectra of the nanoparticles in aqueous solution.

Pd@Au nanoparticles before deposition on the silica support. The HAADF imaging technique provides $z$-contrast, making the Pd shell appear less intense than the Au core. The observed Pd shell thickness corresponds closely with the number of monolayers expected, as calculated from the amount of $\mathrm{Na}_{2} \mathrm{PdCl}_{4}(\mathrm{aq})$ introduced into each Au seed solution, deviating only in the case of the $3.8 \mathrm{Pd} @ A u$ particles (see Table S1, Supporting Information). These and other images were used to obtain the shell thicknesses of $0.7,1.9$, and 3.8 atomic monolayers for the core-shell particles. Here, 0.7 indicates an incomplete monolayer. Figure 1D shows that the $520 \mathrm{~nm}$ peak characteristic of $\mathrm{Au}$ nanoparticles blue shifts and disappears upon the addition of Pd.

TEM size distributions of the Au NPs and the AuPd NPs are shown in Figure 2. The Au seeds are $4.3 \pm 0.6 \mathrm{~nm}$ in diameter. The calculated average diameters of the $0.7,1.9$, and $3.8 \mathrm{Pd} @$ $\mathrm{Au}$ particles are $4.6 \pm 0.6,4.9 \pm 0.6$, and $5.2 \pm 0.8 \mathrm{~nm}$, respectively. The relative standard deviation, representing the polydispersity of the particles, is $13.2 \pm 1.3 \%$ for all of the particles. The average size of the Au seed was subtracted from the average sizes of the Pd@Au particles to give the average shell thicknesses shown in Figure 2.

After depositing the nanoparticles onto the silica support, the compositions of the catalysts were analyzed by ICP-AES. This data was used to calculate the shell thickness using the density of bulk Pd $\left(12.02 \mathrm{~g} / \mathrm{cm}^{3}\right)$ and the $\mathrm{Au}$ seed diameter as determined from bright-field TEM. Table S1, Supporting Information, compares these shell thicknesses derived from ICP-AES with those measured by bright-field TEM and HAADF-STEM, while Table S2, Supporting Information, presents the same data in terms of nanoparticle composition. The values determined by ICP-AES match reasonably well with the shell thicknesses (and thus compositions) calculated from the bright-field TEM images. We hypothesize that the difference between the HAADF and the average values from 

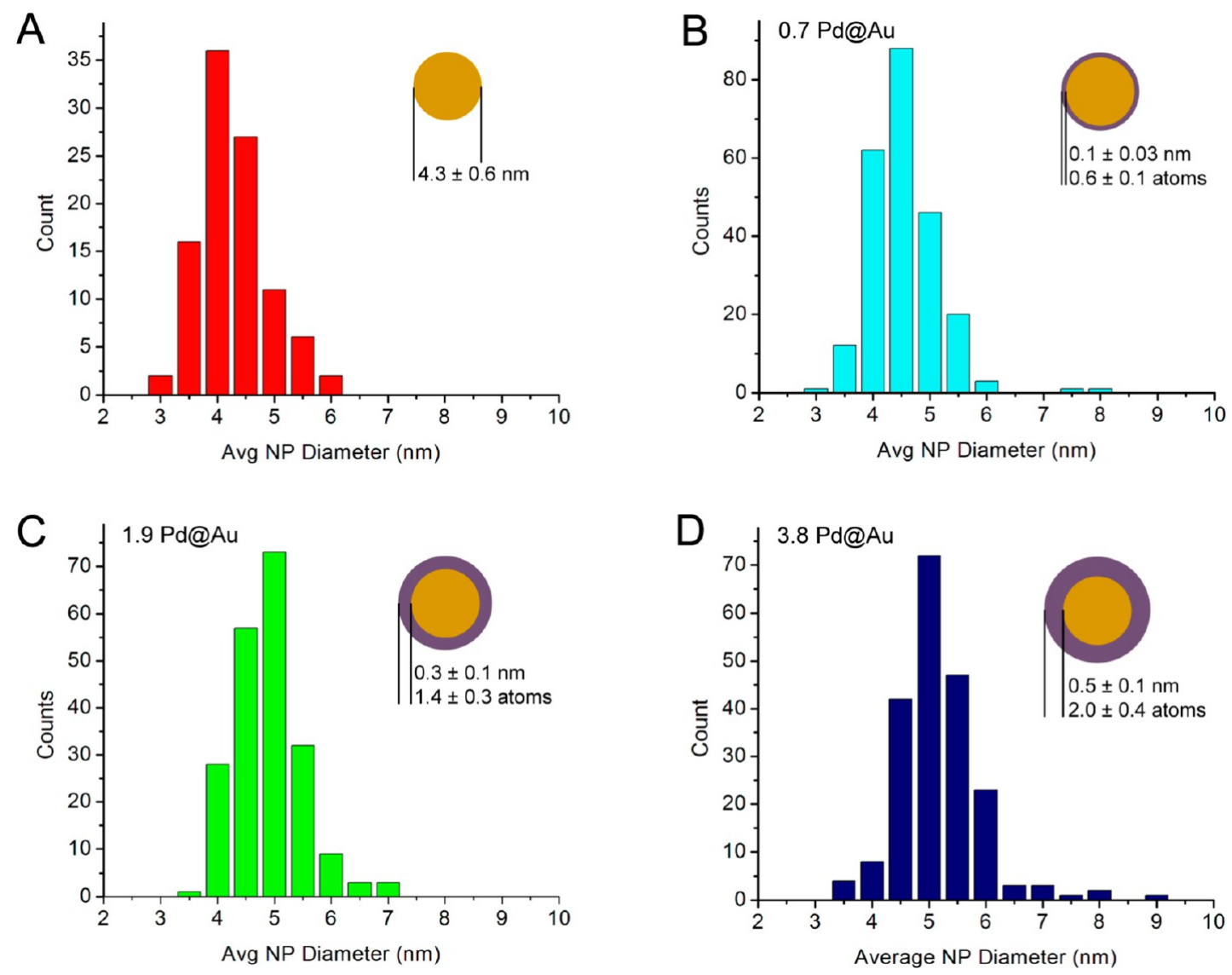

Figure 2. Histograms of the size of $\mathrm{Au}$ and AuPd nanoparticles. The relative standard deviation of the particle size is $13.2 \pm 1.3 \%$ for all of the particles.

TEM and ICP-AES stems from the fact that the Pd shell becomes more jagged and uneven as it grows in thickness, leading to a shell that appears thicker in HAADF-STEM imaging mode than can be accounted for by comparing the ratio of $\mathrm{Pd}$ to $\mathrm{Au}$ in the sample. This hypothesis is supported by observations that the intensity of the Pd shell around the 3.8 Pd@Au in Figure 1C is not uniform and that the outer edge of the particle appears to be irregular. Although they contain some error due to the hypothesized jagged nature of the shell, the HAADF-STEM measurements of shell thickness on individual nanoparticles give a sense of the variance in the composition between the nanoparticles. In comparison, the bright-field TEM and ICP-AES measurements can only give a sense of the average composition, with the variance principally coming from the variance in the diameters of the Au seeds.

Effect of Pretreatment on Catalyst Structure. After the nanoparticles were deposited on the $\mathrm{SiO}_{2}$ support, each catalyst was calcined at $300{ }^{\circ} \mathrm{C}$ to remove PVP. ${ }^{20}$ The catalysts were subsequently heated in flowing $\mathrm{H}_{2}(\mathrm{~g})$ at $300{ }^{\circ} \mathrm{C}$ to reduce any palladium oxide that was formed. The TEM images in Figure 3 reveal the morphological changes to the $\mathrm{Au} / \mathrm{SiO}_{2}$, the $\mathrm{Pd} / \mathrm{SiO}_{2}$ (PVP), and $3.8 \mathrm{Pd} @ \mathrm{Au} / \mathrm{SiO}_{2}$ catalysts after each step in the process. These images show that the monometallic $\mathrm{Pd}$ nanoparticles become larger after heat treatment, indicating that they sinter during the process. In contrast, the $\mathrm{Au}$ and AuPd particles do not sinter, and their size stays relatively constant after heating. Figure 4 quantifies the effect of pretreatment on the size of the nanoparticles, further illustrating the different sintering behaviors of the AuPd and Pd particles. Figure S1, Supporting Information, shows that the
$\mathrm{Pd} / \mathrm{SiO}_{2}$ (PVP) catalyst agglomerates to form larger particles predominantly during calcination and that the size does not increase much more during reduction.

Previous studies have shown $\mathrm{Pd}$ nanoparticles sinter in an oxidative environment at temperatures below $300{ }^{\circ} \mathrm{C}$, presumably due to the formation of $\mathrm{PdO}$, which improves the wetting and migration of Pd across an oxide support. ${ }^{27-29}$ In contrast, the propensity of the AuPd nanoparticles to resist sintering under the same conditions appears to be unprecedented in the literature and suggests that the presence of gold prevents the oxidation of Pd. EDX images in Figure 5 show the very clear transition of the $3.8 \mathrm{Pd} @ \mathrm{Au}$ nanoparticles from a core-shell structure to a homogeneous alloy after calcination. This observation is a second piece of evidence that the presence of gold prevents the formation of $\mathrm{PdO}$ in these nanoparticles, as $\mathrm{PdO}$ does not alloy with $\mathrm{Au}$. Previous electrochemical experiments have also shown that thin layers of palladium deposited on a gold electrode oxidized at a higher applied potential than pure palladium. ${ }^{29}$ Auger electron and photoelectron spectroscopic analysis of AuPd alloyed surfaces have revealed that when the alloy surface is Au-rich, it does not oxidize in the presence of oxygen between 300 and $600{ }^{\circ} \mathrm{C}$. 30 Conversely, Pd-rich surfaces are coated with a layer of PdO under similar conditions. ${ }^{31}$ We hypothesize that, in the Au-rich AuPd system described here, Au inhibits PdO generation under oxidizing conditions, which in turn prevents sintering.

DRIFT spectra of adsorbed CO on the catalysts before and after calcination/reduction provide further evidence that the Pd@Au nanoparticles undergo alloying during pretreatment. CO DRIFT spectra of the as-prepared catalysts after in situ 

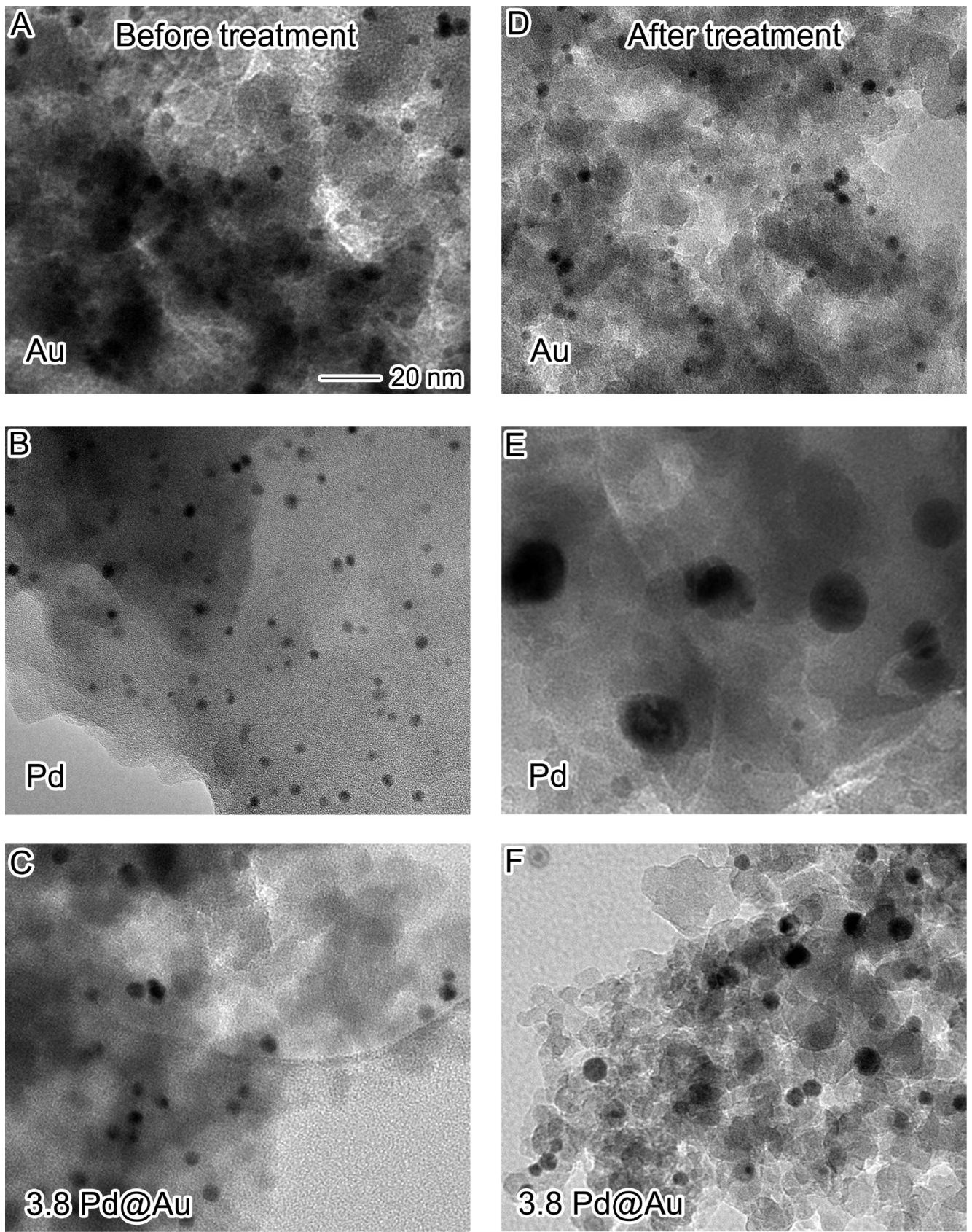

Figure 3. TEM images of $\mathrm{Au} / \mathrm{SiO}_{2}, \mathrm{Pd} / \mathrm{SiO}_{2}$, and $3.8 \mathrm{Pd} @ \mathrm{Au} / \mathrm{SiO}_{2}$ before and after calcination and reduction at $300{ }^{\circ} \mathrm{C}$.

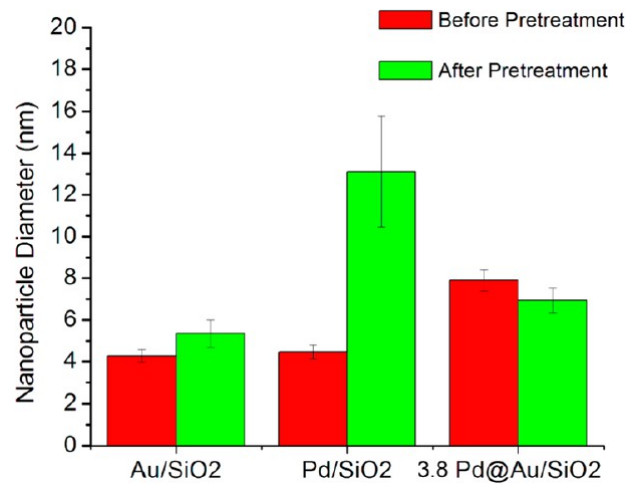

Figure 4. Average diameters of nanoparticles before and after calcination and reduction at $300{ }^{\circ} \mathrm{C}$. treatment in flowing $\mathrm{H}_{2}(\mathrm{~g})$ at $25{ }^{\circ} \mathrm{C}$ (to reduce any superficial $\left.\mathrm{PdO}_{x}\right)$ are shown in Figure 6A. The observed $\mathrm{CO}$ stretching frequencies (2032 and $1932 \mathrm{~cm}^{-1}$ ) are assigned to linear (atop) $\mathrm{CO}$ and 2-fold bridging $\mathrm{CO}$ on $\mathrm{Pd}$, respectively, in agreement with similar frequency assignments for adsorbed $\mathrm{CO}$ on various Pd model catalysts. ${ }^{31-38}$ The relative intensity of the very strong bridging $\mathrm{CO}$ band increases with nominal Pd shell thickness, indicating a higher density of multiatom Pd surface ensembles at higher Pd loadings. The DRIFT spectrum of adsorbed $\mathrm{CO}$ on the $\mathrm{Pd} / \mathrm{SiO}_{2}$ (iw) catalyst, shown in Figure S2A, Supporting Information, exhibits analogous bands at 2094 and $1990 \mathrm{~cm}^{-1}$ that can be assigned to atop and bridging $\mathrm{CO}$; however, they are shifted $\sim 60 \mathrm{~cm}^{-1}$ to higher wavenumbers relative to those observed for the Pd@Au catalysts (Figure 6A). At saturation coverage, peaks in the $1970-1990 \mathrm{~cm}^{-1}$ region have been assigned to doubly bridging $\mathrm{CO}$ on $\mathrm{Pd}(100)$ facets 

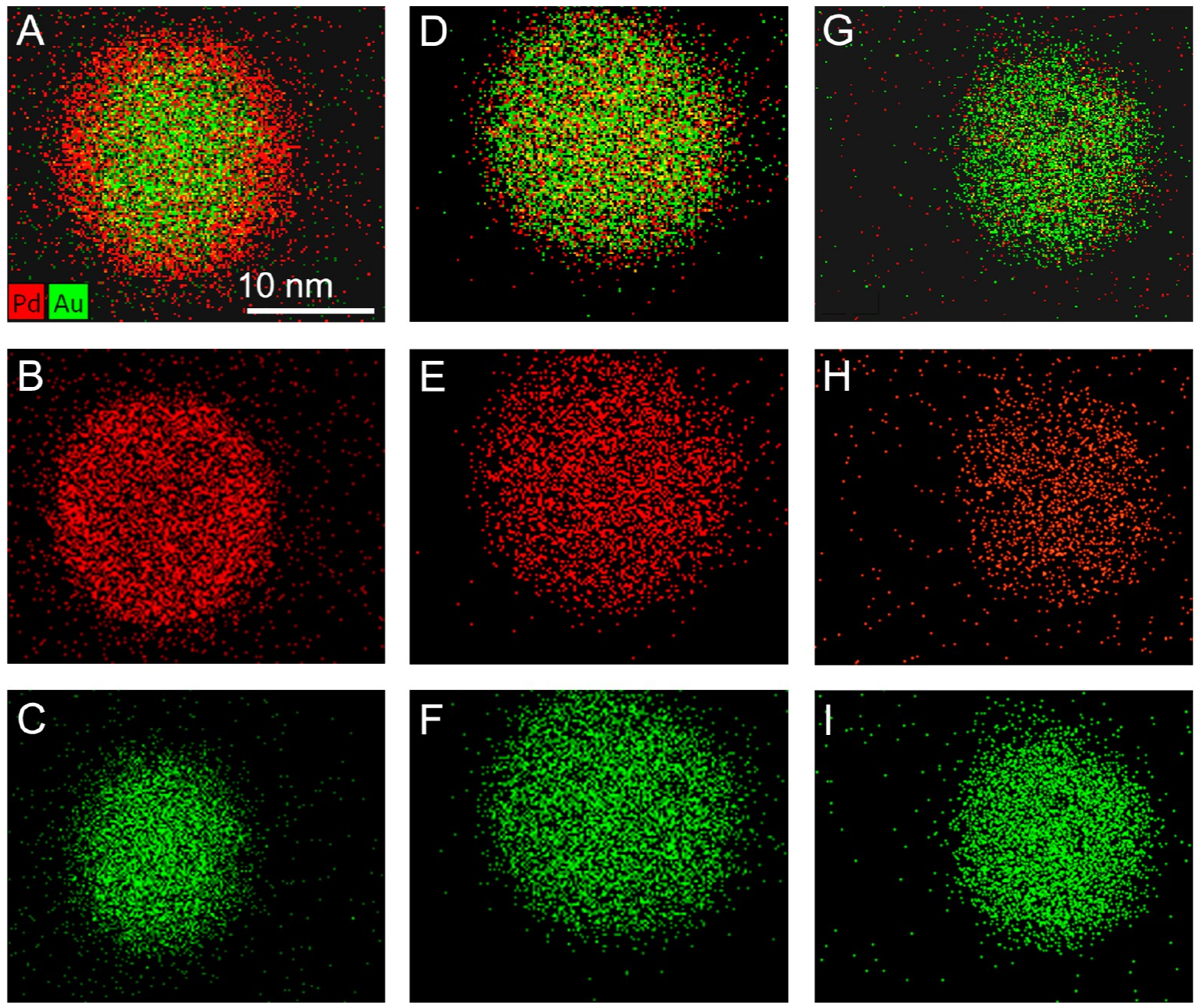

Figure 5. EDX-STEM images of $3.8 \mathrm{Pd} @ \mathrm{Au}(\mathrm{A}-\mathrm{C})$ before pretreatment, $(\mathrm{D}-\mathrm{F})$ after calcination at $300{ }^{\circ} \mathrm{C}$, and $(\mathrm{G}-\mathrm{I})$ after calcination and reduction at $300{ }^{\circ} \mathrm{C}$.

and at particle steps and edges. ${ }^{32}$ The $\mathrm{Pd} / \mathrm{SiO}_{2}$ (iw) catalyst contains faceted $4-5 \mathrm{~nm} \mathrm{Pd}$ nanoparticles (Figure S2B, Supporting Information) that are closely similar in size to the supported Pd@Au core-shell nanoparticles. The decrease (red shift) in $\mathrm{CO}$ stretching frequencies observed when $\mathrm{Au}$ is present in the core of the particle suggests that $\mathrm{Au}$ donates $\mathrm{d}$ electron density to the Pd shell in the Pd@Au configuration. This provides a viable explanation for why $\mathrm{Au}$ inhibits the oxidation of Pd during the calcination step, in that $\mathrm{Au}$ moves the Pd d band center away from the Fermi level and weakens its interaction with adsorbed species, including oxygen. ${ }^{3}$ The $\mathrm{CO}$ DRIFT spectra in Figure 6B were recorded after in situ treatment in flowing $\mathrm{H}_{2}(\mathrm{~g})$ at $100{ }^{\circ} \mathrm{C}$. The spectra are qualitatively similar to those in Figure 6A, indicating retention of a core-shell structure after heating under hydrogen at 100 ${ }^{\circ} \mathrm{C}$. In this case, the intensities of the $\mathrm{CO}$ stretching peaks at $1932 \mathrm{~cm}^{-1}$ for the 1.9 and $3.8 \mathrm{Pd} @ \mathrm{Au} / \mathrm{SiO}_{2}$ catalysts are comparable. We note that, as with previous CO DRIFTS studies, the presence of PVP on the particles in Figure 6A,B did not prevent the adsorption of $\mathrm{CO} .{ }^{39}$

There are three significant changes in the CO DRIFT spectra after calcination and reduction of the $\mathrm{Pd} @ \mathrm{Au} / \mathrm{SiO}_{2}$ catalysts (Figure 6C). First, a linear $\mathrm{Au}-\mathrm{CO}$ stretch at $2100 \mathrm{~cm}^{-1}$ appears in each of the spectra. ${ }^{33-36}$ This indicates that $\mathrm{Au}$ atoms have migrated to the surface of the particles. This conclusion is reinforced by the observation that the intensity of the linear $\mathrm{Pd}-\mathrm{CO}$ stretch relative to the 2 -fold $\mathrm{Pd}-\mathrm{CO}$ bridging stretch is larger in all cases, indicating the break-up of multiatom Pd ensembles. There is also a $28 \mathrm{~cm}^{-1}$ blue shift of the Pd-CO linear and 2-fold stretches to 2060 and $1960 \mathrm{~cm}^{-1}$, respectively. The blue shift of these $\mathrm{CO}$ stretching frequencies may indicate that a subtle shift of $\mathrm{d}$ electron density from $\mathrm{Pd}$ to $\mathrm{Au}$ occurs upon conversion from a core-shell to an alloy structure; however, this shift may also be due to variations in dipole-dipole coupling that can also affect $\mathrm{CO}$ stretching frequencies. ${ }^{3,33}$ The $\mathrm{CO}$ frequencies remain red-shifted from the typical linear and 2-fold bridging $\mathrm{CO}$ stretches observed for $\mathrm{Pd} / \mathrm{SiO}_{2}$ (iw) (2090 and $1990 \mathrm{~cm}^{-1}$, respectively), implying that there is electron transfer from $\mathrm{Au}$ to the $\mathrm{Pd} \mathrm{d}$ band in both the core-shell and alloy structures. ${ }^{33,37}$ We note the small shoulder at $2050 \mathrm{~cm}^{-1}$ that closely matches a shoulder assigned by Marx et al. as a linear $\mathrm{Au}-\mathrm{CO}$ species on AuPd alloy nanoparticles and tentatively assign this shoulder as $\mathrm{CO}$ bound to surface $\mathrm{Au}$ on the AuPd alloy catalysts investigated in this study. $^{33}$

Selectivity of AuPd Nanoparticles in Limonene Conversion. The reaction data in Figure $7 \mathrm{~A}$ demonstrate that the solution-synthesized catalysts were active for the conversion of limonene to $p$-cymene. The yield of $p$-cymene was $65.5 \%, 83.2 \%$, and $84.1 \%$ over the $10.9 \%, 20 \%$, and $28.5 \%$ 

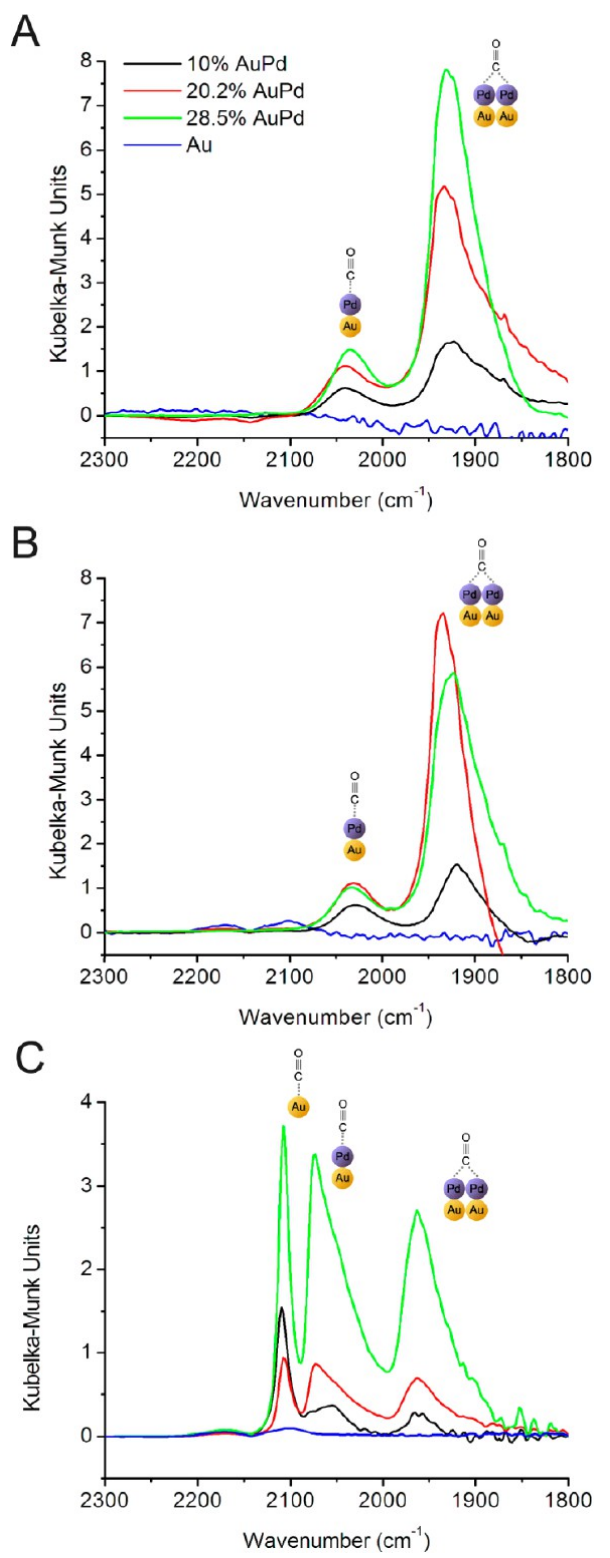

Figure 6. DRIFT spectra of adsorbed $\mathrm{CO}$ on supported $\mathrm{Pd} @ \mathrm{Au} / \mathrm{SiO}_{2}$ catalysts (A) after heating in flowing $\mathrm{H}_{2}(\mathrm{~g})$ at $25^{\circ} \mathrm{C}$, (B) after heating in flowing $\mathrm{H}_{2}(\mathrm{~g})$ at $100{ }^{\circ} \mathrm{C}$, and $(\mathrm{C})$ after calcination and reduction at $300{ }^{\circ} \mathrm{C}$.

AuPd catalysts, respectively, with $100 \%$ conversion of limonene. The conversion of limonene over the $\mathrm{Au} / \mathrm{SiO}_{2}$ catalyst and silica control was $54 \%$ and $60 \%$, respectively. Only $18.6 \%$ of the limonene was converted to $p$-cymene over the $\mathrm{Au} / \mathrm{SiO}_{2}$ catalyst, and a significant portion of the rest of the product stream comprised unidentified products. The $\mathrm{Pd} / \mathrm{SiO}_{2}$ catalysts all performed similarly to one another, fully converting limonene and yielding approximately $80 \%$ p-cymene. In addition to $\rho$-cymene, the Pd nanoparticle catalyst yielded $\alpha$ terpinene and $\rho$-menthane, while the Pd catalysts prepared by incipient wetness and ion exchange yielded only $p$-menthane. The $10 \%$ AuPd catalyst yielded $\alpha$-terpinene as well, but the $20 \%$ and $28.5 \%$ AuPd catalysts did not. Figure $7 \mathrm{~B}$ shows the $\mathrm{Au} / \mathrm{SiO}_{2}$ catalyst and silica readily deactivated, whereas the productivity of the $\mathrm{Pd}$-containing catalysts was relatively constant with time on stream.
Previous work suggests that $\alpha$-limonene conversion to $p$ cymene over silica-supported Pd catalysts proceeds via a twostep hydrogenation/dehydrogenation pathway, in which $p$ menthane is an intermediate and isomers are produced as byproducts only in the absence of $\mathrm{Pd}$ or $\mathrm{H}_{2}(\mathrm{~g}){ }^{22,38}$ However, our results suggest that silica-supported $\mathrm{Pd}$ and AuPd catalysts produce $p$-cymene by an isomerization-dehydrogenation pathway, similar to that reported for solution-phase $\mathrm{Pd}$ nanoparticles. ${ }^{22}$ We base this conclusion on the very low yield of $p$-cymene produced over each catalyst when $p$ menthane was employed as the reactant at $250{ }^{\circ} \mathrm{C}$ (Table 1). This result is surprising given that $p$-cymene is the thermodynamically favored product at this temperature. ${ }^{22}$ If $p$-cymene were primarily produced via reversible dehydrogenation of $p$-menthane, one would expect to see a pattern in the turnover frequencies (TOFs) of the catalysts that is similar to the yields of $p$-cymene in Figure 7A. However, there is no correspondence between the TOFs shown in Table 1 and the selectivity toward $p$-cymene in Figure 7A. Given these results, we propose Scheme 1 as the pathway of conversion from limonene to $p$-cymene, with $p$-menthane being formed as a byproduct rather than an intermediate in the production of $p$ cymene.

Finally, we note that the $10 \%$ AuPd catalyst has the highest turnover frequency (TOF) for $p$-menthane dehydrogenation. All of the other supported Pd catalysts have $p$-menthane TOFs in the $\sim 10-20 \mathrm{~h}^{-1}$ range. It has previously been observed that small islands of Pd deposited on Au surfaces evolve hydrogen at higher rates than a Pd surface. ${ }^{40}$ This enhancement could be attributed to surface diffusion of atomic hydrogen from Pd sites to the surrounding inert $\mathrm{Au}$ atoms, which makes it easier for hydrogen to associatively desorb from the catalyst surface. ${ }^{25}$ An analogous effect might be responsible for the higher activity of the $10 \% \mathrm{AuPd}$ surface for $p$-menthane dehydrogenation. The other two AuPd/ $\mathrm{SiO}_{2}$ catalysts have TOFs of $20 \mathrm{~h}^{-1}$, similar to the value for the highly dispersed $\mathrm{Pd} / \mathrm{SiO}_{2}$ (ie), suggesting a possible ensemble-size effect.

\section{CONCLUSIONS}

We report the synthesis of monodisperse, well-defined $\mathrm{Au}$ nanoparticles with $\mathrm{Pd}$ shells of varying thickness in a catalytically relevant size range $(\leq 5 \mathrm{~nm})$. These core-shell particles were deposited on $\mathrm{SiO}_{2}$, calcined to remove PVP, and reduced to obtain a set of alloy AuPd nanoparticle catalysts with three different Pd contents. Examination of changes in particle size by TEM and changes in morphology by EDX before and after calcination under oxygen at $300{ }^{\circ} \mathrm{C}$ indicate the addition of $\mathrm{Au}$ to a $\mathrm{Pd}$ nanoparticle can prevent its oxidation and thus prevent its migration and sintering on an oxide support. CO DRIFTS confirmed the diffusion of $\mathrm{Au}$ to the surface of the particles after oxidation and reduction at 300 ${ }^{\circ} \mathrm{C}$, and the transfer of electron density from $\mathrm{Au}$ to $\mathrm{Pd}$. The AuPd alloy catalysts were active for the conversion of limonene to $p$-cymene; the particles containing greater than $20 \% \mathrm{Pd}$ exhibited $p$-cymene yields $(\sim 80 \%)$ approximately equivalent to that observed for the Pd catalysts prepared by incipient wetness and ion exchange. The AuPd catalyst with the lowest Pd content $(10.9 \%)$ exhibited a TOF for $p$-menthane dehydrogenation about an order of magnitude greater than catalysts with higher Pd contents. The catalytic results presented here suggest $p$-cymene is formed through the formation of an $\alpha$-terpinene intermediate rather than through the dehydrogenation of $p$ menthane. 
A

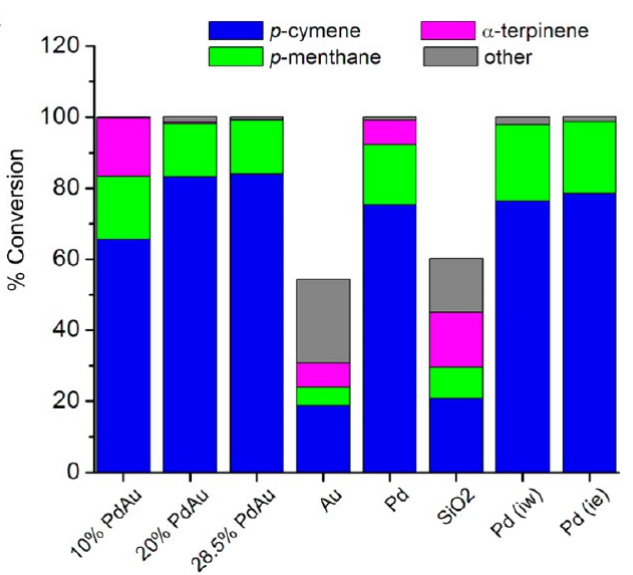

B

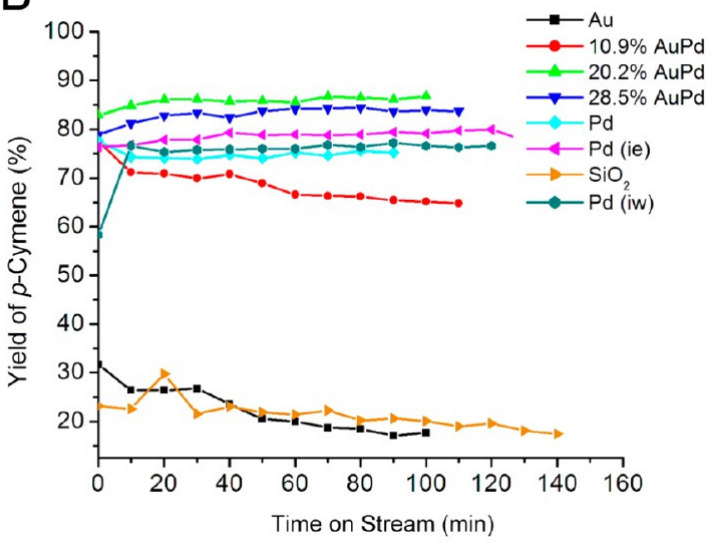

Figure 7. (A) Percent conversion of $\alpha$-limonene to $p$-cymene, $p$-menthane, $\alpha$-terpinene, and other unidentified products over each catalyst and the silica support. The full height of each bar signifies the percent conversion of limonene, while the height of each product represents the percent yield. (B) The yield of $p$-cymene as a function of time on stream for each catalyst at $250{ }^{\circ} \mathrm{C}$.

Table 1. CO Adsorbed $(\mu \mathrm{mol} / \mathrm{g})$ of Total Catalyst (Metal and Silica Support); $p$-Menthane Conversion Refers to the Percentage of Menthane Dyhydrogenated to Form $p$ Cymene; TOF Refers to the $\mathrm{mol} / \mathrm{h}$ of $p$-Menthane Converted to $p$-Cymene per mol CO Adsorbed; $p$-Menthane Feed Rate Was $6 \mu \mathrm{L} / \mathrm{min}$, the Reaction Temperature Was $250{ }^{\circ} \mathrm{C}$, and the Catalyst Mass for Each Run Was $0.250 \mathrm{~g}$

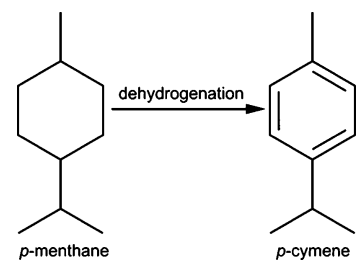

\begin{tabular}{lccc}
\multicolumn{1}{c}{ catalyst } & $\begin{array}{c}\mathrm{CO} \text { adsorbed } \\
(\mu \mathrm{mol} / \mathrm{g})\end{array}$ & $\begin{array}{c}p \text {-menthane } \\
\text { conversion }(\%)\end{array}$ & \multicolumn{1}{c}{ TOF $\left(\mathrm{h}^{-1}\right)$} \\
$10 \% \mathrm{AuPd}$ & $0.69 \pm 0.1$ & $1.42 \pm 0.008$ & $162.7 \pm 17.8$ \\
$20 \% \mathrm{AuPd}$ & $5.13 \pm 0.6$ & $1.39 \pm 0.001$ & $20.8 \pm 2.4$ \\
$28.5 \% \mathrm{AuPd}$ & $5.51 \pm 0.7$ & $1.32 \pm 0.06$ & $16.1 \pm 2.0$ \\
$\mathrm{Pd} / \mathrm{SiO}_{2}$ & $0.77 \pm 0.2$ & $1.23 \pm 0.001$ & $7.6 \pm 0.09$ \\
$\mathrm{Pd} / \mathrm{SiO}_{2}(\mathrm{ie})$ & $27.1 \pm 1.4$ & $7.17 \pm 0.2$ & $21.3 \pm 0.8$ \\
$\mathrm{Pd} / \mathrm{SiO}_{2}(\mathrm{iw})$ & $15.7 \pm 0.8$ & $1.88 \pm 0.09$ & $9.7 \pm 0.3$ \\
\hline
\end{tabular}

Scheme 1. Proposed Scheme of Limonene Conversion to $p$ Cymene and $p$-Menthane

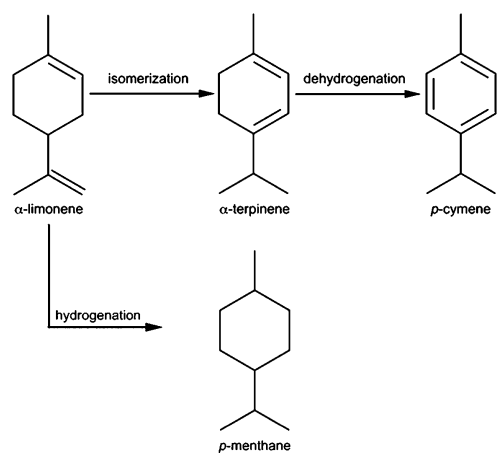

Going forward, we would ideally like to compare the catalytic properties of the core-shell AuPd particles with the properties of the alloys to gain further insights into the relative contributions of ensemble, ligand, and spillover effects to a catalyst's activity and selectivity. ${ }^{40}$ However, for AuPd nanoparticles in a catalytically relevant size range, we show that such an analysis can only be performed for relatively lowtemperature reactions; otherwise, the core-shell nanoparticles will alloy. Elimination of the need to burn off PVP at $300{ }^{\circ} \mathrm{C}$ is a secondary prerequisite to comparing the properties of the core-shell and alloyed nanoparticles. Although the AuPd synthesis did not require the use of PVP, we found PVP to be helpful in dispersing the nanoparticles evenly across the $\mathrm{SiO}_{2}$ and prevent their aggregation during drying. Thus, an improved method for depositing the nanoparticles on a support would eliminate the need for PVP. Although obstacles remain, this work represents an important step toward understanding how to prepare and characterize model nanoparticle catalysts for testing mechanistic hypotheses. In particular, the quantification of the per particle variance in composition by simply measuring changes in size may facilitate the preparation and comparison of catalysts that are not only monodisperse in size but also in composition.

\section{ASSOCIATED CONTENT}

\section{S Supporting Information}

Comparison of the Pd shell thicknesses calculated using ICPAES, bright-field TEM, and HAADF-STEM measurements; bright-field TEM images of the $\mathrm{Pd} / \mathrm{SiO}_{2}$ (PVP) before pretreatment, after calcination, and after calcination and subsequent reduction; and the DRIFT spectrum and a HAADF-STEM image of the $\mathrm{Pd} / \mathrm{SiO}_{2}$ catalyst prepared by incipient wetness impregnation. This material is available free of charge via the Internet at http://pubs.acs.org.

\section{AUTHOR INFORMATION}

\section{Corresponding Author}

*E-mail: benjamin.wiley@duke.edu (B.J.W.); lamb@ncsu.edu (H.H.L.).

\section{Notes}

The authors declare no competing financial interest.

\section{ACKNOWLEDGMENTS}

We acknowledge support from the NSF EFRI HyBi grant (EFRI-0937721), start-up funds from Duke University, and ORNL's Share User Facility, which is sponsored by the 
Scientific User Facilities Division, Office of Basic Energy Sciences, U.S. Department of Energy. A.R.W. is supported through the National Science Foundation Graduate Research Fellow Program. This work made use of the Analytical Instrumentation Facility at NCSU.

\section{REFERENCES}

(1) Coq, B.; Figueras, F. Bimetallic Palladium Catalysts: Influence of the Co-Metal on the Catalyst Performance. J. Mol. Catal. A: Chem. 2001, 173, 117-134.

(2) Ferrer, D.; Torres-Castro, A.; Gao, X.; Sepúlveda-Guzmán, S.; Ortiz-Méndez, U.; José-Yacamán, M. Three-Layer Core/Shell Structure in $\mathrm{Au}-\mathrm{Pd}$ Bimetallic Nanoparticles. Nano Lett. 2007, 7, 1701-1705.

(3) Gao, F.; Goodman, D. W. Pd-Au Bimetallic Catalysts: Understanding Alloy Effects from Planar Models and (Supported) Nanoparticles. Chem. Soc. Rev. 2012, 41, 8009-8020.

(4) Enache, D. I.; Edwards, J. K.; Landon, P.; Solsona-Espriu, B.; Carley, A. F.; Herzing, A. A.; Watanabe, M.; Kiely, C. J.; Knight, D. W.; Hutchings, G. J. Solvent-Free Oxidation of Primary Alcohols to Aldehydes Using $\mathrm{Au}-\mathrm{Pd} / \mathrm{TiO}_{2}$ Catalysts. Science 2006, 311, 362-365.

(5) Chen, Y.; Lim, H.; Tang, Q.; Gao, Y.; Sun, T.; Yan, Q.; Yang, Y. Solvent-Free Aerobic Oxidation of Benzyl Alcohol over Pd Monometallic and $\mathrm{Au}-\mathrm{Pd}$ Bimetallic Catalysts Supported on SBA16 Mesoporous Molecular Sieves. Appl. Catal., A 2010, 380, 55-65.

(6) Ham, H. C.; Hwang, G. S.; Han, J.; Nam, S. W.; Lim, T. H. Geometric Parameter Effects on Ensemble Contributions to Catalysis: $\mathrm{H}_{2} \mathrm{O}_{2}$ Formation from $\mathrm{H}_{2}$ and $\mathrm{O}_{2}$ on AuPd Alloys. A First Principles Study. J. Phys. Chem. C 2010, 114, 14922-14928.

(7) Liu, P.; Norskov, J. K. Ligand and Ensemble Effects in Adsorption on Alloy Surfaces. Phys. Chem. Chem. Phys. 2001, 3, 3814-3818.

(8) Kumar, D.; Chen, M. S.; Goodman, D. W. Synthesis of Vinyl Acetate on Pd-Based Catalysts. Catal. Today 2007, 123, 77-85.

(9) Rebelli, J.; Detwiler, M.; Ma, S.; Williams, C. T.; Monnier, J. R. Synthesis and Characterization of $\mathrm{Au}-\mathrm{Pd} / \mathrm{SiO}_{2}$ Bimetallic Catalysts Prepared by Electroless Deposition. J. Catal. 2010, 270, 224-233.

(10) Meenakshisundaram, S.; Nowicka, E.; Miedziak, P. J.; Brett, G. L.; Jenkins, R. L.; Dimitratos, N.; Taylor, S. H.; Knight, D. W.; Bethell, D.; Hutchings, G. J. Oxidation of Alcohols Using Supported Gold and Gold-Palladium Nanoparticles. Faraday Discuss. 2010, 145, 341-356.

(11) Solsona, B. E.; Edwards, J. K.; Landon, P.; Carley, A. F.; Herzing, A.; Kiely, C. J.; Hutchings, G. J. Direct Synthesis of Hydrogen Peroxide from $\mathrm{H}_{2}$ and $\mathrm{O}_{2}$ Using $\mathrm{Al}_{2} \mathrm{O}_{3}$ Supported $\mathrm{Au}-\mathrm{Pd}$ Catalysts. Chem. Mater. 2006, 18, 2689-2695.

(12) Chai, J.; Li, F.; Hu, Y.; Zhang, Q.; Han, D.; Niu, L. Hollow Flower-Like AuPd Alloy Nanoparticles: One Step Synthesis, SelfAssembly on Ionic Liquid-Functionalized Graphene, and Electrooxidation of Formic Acid. J. Mater. Chem. 2011, 21, 17922-17929.

(13) Pawelec, B.; Venezia, A. M.; La Parola, V.; Cano-Serrano, E.; Campos-Martin, J. M.; Fierro, J. L. G. AuPd Alloy Formation in $\mathrm{Au}-$ $\mathrm{Pd} / \mathrm{Al}_{2} \mathrm{O}_{3}$ Catalysts and Its Role on Aromatics Hydrogenation. Appl. Surf. Sci. 2005, 242, 380-391.

(14) Venezia, A. M.; Parola, V. L.; Pawelec, B.; Fierro, J. L. G. Hydrogenation of Aromatics over $\mathrm{Au}-\mathrm{Pd} / \mathrm{SiO}_{2}-\mathrm{Al}_{2} \mathrm{O}_{3}$ Catalysts; Support Acidity Effect. Appl. Catal., A 2004, 264, 43-51.

(15) Baber, A. E.; Tierney, H. L.; Sykes, E. C. H. Atomic-Scale Geometry and Electronic Structure of Catalytically Important Pd/Au Alloys. ACS Nano 2010, 4, 1637-1645.

(16) Ketchie, W. C.; Murayama, M.; Davis, R. J. Selective Oxidation of Glycerol over Carbon-Supported AuPd Catalysts. J. Catal. 2007, 250, 264-273.

(17) Guczi, L.; Beck, A.; Horváth, A.; Koppány, Z.; Stefler, G.; Frey, K.; Sajó, I.; Geszti, O.; Bazin, D.; Lynch, J. AuPd Bimetallic Nanoparticles on $\mathrm{TiO}_{2}: \mathrm{XRD}, \mathrm{TEM}$, in Situ EXAFS Studies and Catalytic Activity in CO Oxidation. J. Mol. Catal. A: Chem. 2003, 204$205,545-552$.
(18) Xu, J.; Wilson, A. R.; Rathmell, A. R.; Howe, J.; Chi, M.; Wiley, B. J. Synthesis and Catalytic Properties of Au-Pd Nanoflowers. ACS Nano 2011, 5, 6119-6127.

(19) Zhou, W.; Lee, J. Y. Highly Active Core-Shell Au@Pd Catalyst for Formic Acid Electrooxidation. Electrochem. Commun. 2007, 9, $1725-1729$.

(20) Dash, P.; Bond, T.; Fowler, C.; Hou, W.; Coombs, N.; Scott, R. W. J. Rational Design of Supported PdAu Nanoparticle Catalysts from Structured Nanoparticle Precursors. J. Phys. Chem. C 2009, 113, 12719-12730.

(21) Corma, A.; Iborra, S.; Velty, A. Chemical Routes for the Transformation of Biomass into Chemicals. Chem. Rev. 2007, 107, 2411-2502.

(22) Zhao, C.; Gan, W.; Fan, X.; Cai, Z.; Dyson, P. J.; Kou, Y. Aqueous-Phase Biphasic Dehydroaromatization of Bio-Derived Limonene into $p$-Cymene by Soluble Pd Nanocluster Catalysts. J. Catal. 2008, 254, 244-250.

(23) Reddy, K. S. N.; Rao, B. S.; Shiralkar, V. P. Selective Formation of Cymenes over Large Pore Zeolites. Appl. Catal., A 1995, 121, 191201.

(24) Harvey, B. G.; Wright, M. E.; Quintana, R. L. High-Density Renewable Fuels Based on the Selective Dimerization of Pinenes. Energy Fuels 2009, 24, 267-273.

(25) Buhl, D.; Roberge, D. M.; Hölderich, W. F. Production of $p$ Cymene from $\alpha$-Limonene over Silica Supported Pd Catalysts. Appl. Catal., A 1999, 188, 287-299.

(26) Han, J.; Sun, H.; Duan, J.; Ding, Y.; Lou, H.; Zheng, X. Palladium-Catalyzed Transformation of Renewable Oils into Diesel Components. Adv. Synth. Catal. 2010, 352, 1805-1809.

(27) Gabasch, H.; Unterberger, W.; Hayek, K.; Klötzer, B.; Kleimenov, E.; Teschner, D.; Zafeiratos, S.; Hävecker, M.; KnopGericke, A.; Schlögl, R.; Han, J.; Ribeiro, F. H.; Aszalos-Kiss, B.; Curtin, T.; Zemlyanov, D. In Situ XPS Study of Pd(111) Oxidation at Elevated Pressure, Part 2: Palladium Oxidation in the 101 mbar Range. Surf. Sci. 2006, 600, 2980-2989.

(28) Chen, J. J.; Ruckenstein, E. Role of Interfacial Phenomena in the Behavior of Alumina-Supported Palladium Crystallites in Oxygen. J. Phys. Chem. 1981, 85, 1606-1612.

(29) Moss, R. L.; Pope, D.; Davis, B. J.; Edwards, D. H. The Structure and Activity of Supported Metal Catalysts: VIII. Chemisorption and Benzene Hydrogenation on Palladium/Silica Catalysts. J. Catal. 1979, $58,206-219$.

(30) Cadle, S. H. Electrochemical Oxidation of Thin Palladium Films on Gold. Anal. Chem. 1974, 46, 587-590.

(31) Hilaire, L.; Légaré, P.; Holl, Y.; Maire, G. Interaction of Oxygen and Hydrogen with Pd-Au Alloys: An AES and XPS Study. Surf. Sci. 1981, 103, 125-140.

(32) Lear, T.; Marshall, R.; Lopez-Sanchez, J. A.; Jackson, S. D.; Klapotke, T. M.; Baumer, M.; Rupprechter, G.; Freund, H.-J.; Lennon, D. The Application of Infrared Spectroscopy to Probe the Surface Morphology of Alumina-Supported Palladium Catalysts. J. Chem. Phys. 2005, 123, 174706.

(33) Marx, S.; Krumeich, F.; Baiker, A. Surface Properties of Supported, Colloid-Derived Gold/Palladium Mono- and Bimetallic Nanoparticles. J. Phys. Chem. C 2011, 115, 8195-8205.

(34) Dellwig, T.; Rupprechter, G.; Unterhalt, H.; Freund, H. J. Bridging the Pressure and Materials Gaps: High Pressure Sum Frequency Generation Study on Supported Pd Nanoparticles. Phys. Rev. Lett. 2000, 85, 776-779.

(35) Groppo, E.; Bertarione, S.; Rotunno, F.; Agostini, G.; Scarano, D.; Pellegrini, R.; Leofanti, G.; Zecchina, A.; Lamberti, C. Role of the Support in Determining the Vibrational Properties of Carbonyls Formed on Pd Supported on $\mathrm{SiO}_{2}, \mathrm{Al}_{2} \mathrm{O}_{3}, \mathrm{Al}_{2} \mathrm{O}_{3}$, and $\mathrm{MgO}$. J. Phys. Chem. C 2007, 111, 7021-7028.

(36) Ozensoy, E.; Wayne Goodman, D. Vibrational Spectroscopic Studies on CO Adsorption, NO Adsorption CO + NO Reaction on Pd Model Catalysts. Phys. Chem. Chem. Phys. 2004, 6, 3765-3778. 
(37) Kelly, M. J.; Kim, J.; Roberts, G. W.; Lamb, H. H. Characterization of $\mathrm{Pd} / \gamma-\mathrm{Al}_{2} \mathrm{O}_{3}$ Catalysts Prepared Using $\left[\mathrm{Pd}(\mathrm{hfac})_{2}\right]$ in Liquid $\mathrm{CO}_{2}$. Top. Catal. 2008, 49, 178-186.

(38) Xu, X.; Goodman, D. W. An Infrared and Kinetic Study of Carbon Monoxide Oxidation on Model Silica-Supported Palladium Catalysts from 10-9 to 15 Torr. J. Phys. Chem. 1993, 97, 7711-7718.

(39) Borodko, Y.; Lee, H. S.; Joo, S. H.; Zhang, Y.; Somorjai, G. Spectroscopic Study of the Thermal Degradation of PVP-Capped Rh and Pt Nanoparticles in $\mathrm{H}_{2}$ and $\mathrm{O}_{2}$ Environments. J. Phys. Chem. C 2009, 114, 1117-1126.

(40) Santana, J. A.; Rosch, N. Hydrogen Adsorption on and Spillover from $\mathrm{Au}$ - and $\mathrm{Cu}$-Supported $\mathrm{Pt}_{3}$ and $\mathrm{Pd}_{3}$ Clusters: a Density Functional Study. Phys. Chem. Chem. Phys. 2012, 14, 16062-16069. 